\title{
Dopamine attenuates ethanol-induced neuroapoptosis in the developing rat retina via the CAMP/PKA pathway
}

\author{
JUNDE HAN $^{1}$, LINGQI GAO ${ }^{1}$, JING DONG $^{1}$, YINGTIAN WANG ${ }^{1}$, MAZHONG ZHANG $^{2}$ and JIJIAN ZHENG ${ }^{3}$ \\ ${ }^{1}$ Department of Anesthesiology, Shanghai General Hospital, Shanghai Jiao Tong University School of Medicine, \\ Shanghai 201600; Departments of ${ }^{2}$ Anesthesiology and Pediatric Clinical Pharmacology Laboratory, and ${ }^{3}$ Anesthesiology, \\ Shanghai Children's Medical Center, Shanghai Jiao Tong University School of Medicine, Shanghai 200127, P.R. China
}

Received June 24, 2016; Accepted April 24, 2017

DOI: $10.3892 / \mathrm{mmr} .2017 .6823$

\begin{abstract}
Apoptosis has been identified as the primary cause of fetal alcohol spectrum disorder (FASD), and the development of methods to prevent and treat FASD have been based on the mechanisms of alcohol-induced apoptosis. The present study aimed to explore the effects of dopamine on alcohol-induced neuronal apoptosis using whole-mount cultures of rat retinas (postnatal day 7). Retinas were initially incubated with ethanol $(100,200$ or $500 \mathrm{mM})$, and in subsequent analyses retinas were co-incubated with ethanol $(200 \mathrm{mM})$ and dopamine $(10 \mu \mathrm{M})$. In addition, several antagonists and inhibitors were used, including a D1 dopamine receptor (D1R) antagonist (SCH23390; $10 \mu \mathrm{M}$ ), a D2R antagonist (raclopride; $40 \mu \mathrm{M}$ ), an adenosine $\mathrm{A} 2 \mathrm{~A}$ receptor (AA2AR) antagonist (SCH58261; $100 \mathrm{nM}$ ), an adenylyl cyclase (AC) inhibitor (SQ22536; $100 \mu \mathrm{M})$ and a PKA inhibitor (H-89; $1 \mu \mathrm{M})$. The results demonstrated that exposure increased neuroapoptosis in the retinal ganglion cell layer (GCL) in a dose-dependent manner. Dopamine treatment significantly attenuated ethanol-induced neuronal apoptosis. D1R, D2R and AA2AR antagonists partially inhibited the protective effects of dopamine against ethanol-induced apoptosis; similar results were observed with $\mathrm{AC}$ and PKA inhibitor treatments. In summary, the present study demonstrated that dopamine treatment may be able to attenuate alcohol-induced neuroapoptosis in the developing rat
\end{abstract}

Correspondence to: Professor Mazhong Zhang, Department of Anesthesiology and Pediatric Clinical Pharmacology Laboratory, Shanghai Children's Medical Center, Shanghai Jiao Tong University School of Medicine, 1678 Dongfang Road, Pudong, Shanghai 200127, P.R. China

E-mail: zmzscmc@shsmu.edu.cn

Professor Jijian Zheng, Department of Anesthesiology, Shanghai Children's Medical Center, Shanghai Jiao Tong University School of Medicine, 1678 Dongfang Road, Pudong, Shanghai 200127, P.R. China

E-mail: zhengjijian626@sina.com

Key words: dopamine, alcohol, neuronal apoptosis, retina ganglion cell, cyclic adenosine monophosphate/protein kinase A retina by activating D1R, D2R and AA2AR, and by upregulating cyclic AMP/protein kinase A signaling.

\section{Introduction}

Prenatal alcohol exposure may result in fetal alcohol syndrome (FAS), a severe form of fetal alcohol spectrum disorder (FASD); symptoms of FAS include craniofacial malformation, structural abnormalities of the nervous systems and long-term neurobehavioral disorders $(1,2)$. Neurobehavioral disorders are the primary manifestation of FAS and affect up to $2-5 \%$ of young children in the United States and Western Europe $(3,4)$. The precise mechanisms of FASD development remain largely unknown, and there are no effective clinical treatments to prevent FASD except for the avoidance of alcohol consumption.

Previous studies in both animals and humans have reported that alcohol exposure during early prenatal development was associated with the loss of neuronal mass or a reduction in the volume of specific brain regions $(2,5,6)$. Other studies using rodents or non-human primates have demonstrated that a single exposure to alcohol during a period equivalent to the human third trimester was able to induce widespread apoptosis of neurons and glia $(5,7)$. Once neuronal and glial apoptosis occur, secondary mechanisms begin to compensate for the alcohol-induced apoptotic injuries and may result in permanent damage. Therefore, apoptosis is considered to be the primary mechanism that results in the occurrence of FASD, and modulating apoptosis may be key to preventing and treating FASD (8).

Dopamine is a neurotransmitter that is widely expressed in the brain and retina, and is often used as a vasoactive drug. Dopamine activates two types of dopamine receptor, the D1-like (such as D1 and D5) and D2-like (such as D2, D3 and D4) families, and modulates intracellular cyclic adenosine monophosphate (cAMP) levels $(9,10)$. A recent study demonstrated that alcohol exposure increased neuroapoptosis through the downregulation of D1 dopamine receptor (D1R) expression in prenatal rat brains (11), which indicated that the dopaminergic system may be involved in alcohol-induced neuronal apoptosis. In addition, dopamine has been revealed to protect neurons against glutamate-induced neuronal death through both D1and D2-like receptors (12), and activation of the D2 dopamine 
receptor (D2R) inhibited neonatal cardiomyocyte apoptosis induced by ischemia/reperfusion injury (13). However, whether dopamine, or the activation of dopamine receptor subtypes, protects against alcohol-induced neuroapoptosis in the developing retina remains unclear. In addition, D2R and AA2AR may form heterodimers and activation by dopamine may activate $\mathrm{AC}$, resulting in upregulation of cAMP $(10,14)$. Whether activation of the heteromeric complexes protects against alcohol-induced neuroapoptosis remains unknown.

The cAMP/protein kinase A (PKA) signal transduction pathway has been reported to serve an important role in the survival of neuronal populations in the neonatal nervous system, including retinal ganglion cells (15-17). However, the role of intracellular cAMP or PKA levels in alcohol-induced neuroapoptosis remains unclear, as both up- and downregulation of intracellular cAMP or PKA levels have been reported to induce neuronal apoptosis (18-22).

The present study used immunohistochemistry and terminal deoxynucleotidyl-transferase-mediated dUTP nick end labeling (TUNEL) to explore the effects and mechanisms of dopamine on alcohol-induced neuronal apoptosis in the developing rat retina.

\section{Materials and methods}

Animals. A total of 55 postnatal day 7 (P7) Sprague-Dawley rat pups weighing 15-17 g were obtained from the Experimental Animal Center at the Shanghai General Hospital (Shanghai, China). Male and female rat pups were included and were kept with their mother under a 12 -h light/dark cycle, at $35-37^{\circ} \mathrm{C}$, with food and water available. All experimental procedures were reviewed and approved by the Animal Care Committee at the Shanghai General Hospital, Shanghai Jiao Tong University School of Medicine (Shanghai, China) and were conducted following the guidelines of the Care and Use of Laboratory Animals published by The US National Institutes of Health and The Association of Research in Vision and Ophthalmology Statement for the Use of Animals in Ophthalmic and Vision Research. Every effort was made to minimize the number and discomfort of animals during all experimental procedures.

Experimental procedures. The basic experimental protocol was slightly modified from a previously published study (23). Briefly, all experimental rat pups were sacrificed by decapitation and their eyes were rapidly dissected using fine scissors and transferred to an ice-cold $\left(0-4^{\circ} \mathrm{C}\right)$ bath of artificial cerebrospinal fluid for $\sim 2$ min prior to being cut open [ACSF; $\mathrm{NaCl}(119 \mathrm{mM}), \mathrm{KCl}(2.5 \mathrm{mM}), \mathrm{K}_{2} \mathrm{HPO}_{4}(1.0 \mathrm{mM})$, $\mathrm{CaCl}_{2}(2.5 \mathrm{mM}), \mathrm{MgCl}_{2}(1.3 \mathrm{mM}), \mathrm{NaHCO}_{3}(26.2 \mathrm{mM})$ and D-Glucose $(11 \mathrm{mM})]$. The bath was continuously bubbled with a $95 \% \mathrm{O}_{2} / 5 \% \mathrm{CO}_{2}$ gas mixture. Approximately one-fifth of the eyeball circumference at the edge of the cornea and sclera was cut using ophthalmology scissors to facilitate the perfusion of ACSF and interventional drugs into the retina. Following $1 \mathrm{~h}$ recovery in normal ACSF at $37^{\circ} \mathrm{C}$ bubbled with a $95 \% \mathrm{O}_{2} / 5 \% \mathrm{CO}_{2}$ gas mixture, the recovered eyeballs were incubated with different concentrations of ethanol, dopamine or various antagonists, either in combination or separately, in $\mathrm{ACSF}$ at $37^{\circ} \mathrm{C}$ with a $95 \% \mathrm{O}_{2} / 5 \% \mathrm{CO}_{2}$ gas mixture for $5 \mathrm{~h}$, according to a previous study (24). In order to reduce ethanol evaporation from the ACSF and to keep the ethanol concentration of the ACSF at a stable level, cell culture dishes, in which eyeballs were cultured, were placed in a larger cell culture dish containing ACSF. Following the various drug treatments, the retinas were dissected from the eyeballs and the flatter part of the retina between the central and peripheral areas was selected for immunohistochemistry and TUNEL experiments.

Drugs. Ethanol was purchased from Sinopharm Chemical Reagent Co., Ltd. (Shanghai, China) and dopamine was purchased from Fujian GuTian Pharmaceutical Company (Fujian, China). All inhibitors and antagonists were purchased from Sigma-Aldrich (Merck KGaA, Darmstadt, Germany), including the following: SCH23390, a D1R antagonist; raclopride, a D2R antagonist; SCH58261, an adenosine A2A receptor (AA2AR); SQ22536, an adenylyl cyclase (AC) inhibitor; and H-89, a PKA inhibitor (24). All drugs were dissolved in ACSF except SCH58261; SCH58261 was first dissolved in DMSO to form a stock solution, and the concentration of DMSO in the working solution was $<0.1 \%$ as in a previous study (24).

Caspase-3 immunohistochemistry. Following drug treatments, eyeballs were quickly transferred to an ice-cold $\left(0-4^{\circ} \mathrm{C}\right)$ bath of ACSF and the retina was immediately detached and fixed in $4 \%$ paraformaldehyde at $4^{\circ} \mathrm{C}$ for $24 \mathrm{~h}$. Subsequent to the retinas being embedded in paraffin, retinal sections (4-6 $\mu$ m-thick) were obtained with a Leica RM2135 Rotary Microtome (Leica Microsystems GmbH, Wetzlar, Germany) and mounted onto slides. Subsequently, the retinal sections were deparaffinized and rehydrated (with $100 \%$ xylene, $100 \%$ ethanol, $95 \%$ ethanol, $85 \%$ ethanol, $75 \%$ ethanol and double distilled water), endogenous peroxidases were inactivated with $3 \%$ hydrogen peroxide at room temperature for $10 \mathrm{~min}$, and 0.1 M EDTA ( $\mathrm{pH} 9.0$ ) was used for heat-induced $\left(95-97^{\circ} \mathrm{C}\right.$ ) antigen retrieval for 8-10 min. Retinal sections were rinsed in PBS, blocked with $10 \%$ donkey serum (cat. no. D9663; Merck KGaA) in PBS at room temperature for $10 \mathrm{~min}$ and incubated with rabbit anti-cleaved caspase-3 antibody (1:300; cat. no. 9661; Cell Signaling Technology, Danvers, MA, USA) overnight at $4^{\circ} \mathrm{C}$. Following rinsing in PBS, retinal sections were incubated with a horseradish peroxidase-conjugated goat anti-rabbit immunoglobulin $\mathrm{G}$ secondary antibody (cat. no. PV-9001; ZSGB-BIO, Beijing, China) at $37^{\circ} \mathrm{C}$ for $1 \mathrm{~h}$ and stained by chromogenic reaction via 3,3'-diaminobenzidine (DAB; cat. no. ZLI-9017; ZSGB-BIO, Beijing, China). All sections were then counterstained with hematoxylin to stain the nuclei blue. Finally, sections were dehydrated (with $75 \%$ ethanol, $85 \%$ ethanol, $95 \%$ ethanol, $100 \%$ ethanol and $100 \%$ xylene) and mounted using neutral balsam (cat. no. 10004160, Sinopharm Chemical Reagent Co., Ltd.) for microscopic examination (Leica DM5500B; Leica Microsystems GmbH).

TUNEL assay. A TUNEL kit (Roche Applied Science, Penzberg, Germany) was used for the TUNEL assay. Retinal sections from the various treatment groups were deparaffinized and rehydrated as mentioned above. The sections were washed with PBS, treated with proteinase $\mathrm{K}$ at $37^{\circ} \mathrm{C}$ for $30 \mathrm{~min}$ and quenched with $3 \%$ hydrogen peroxide at room temperature for $10 \mathrm{~min}$. Following washing with PBS, the sections were 

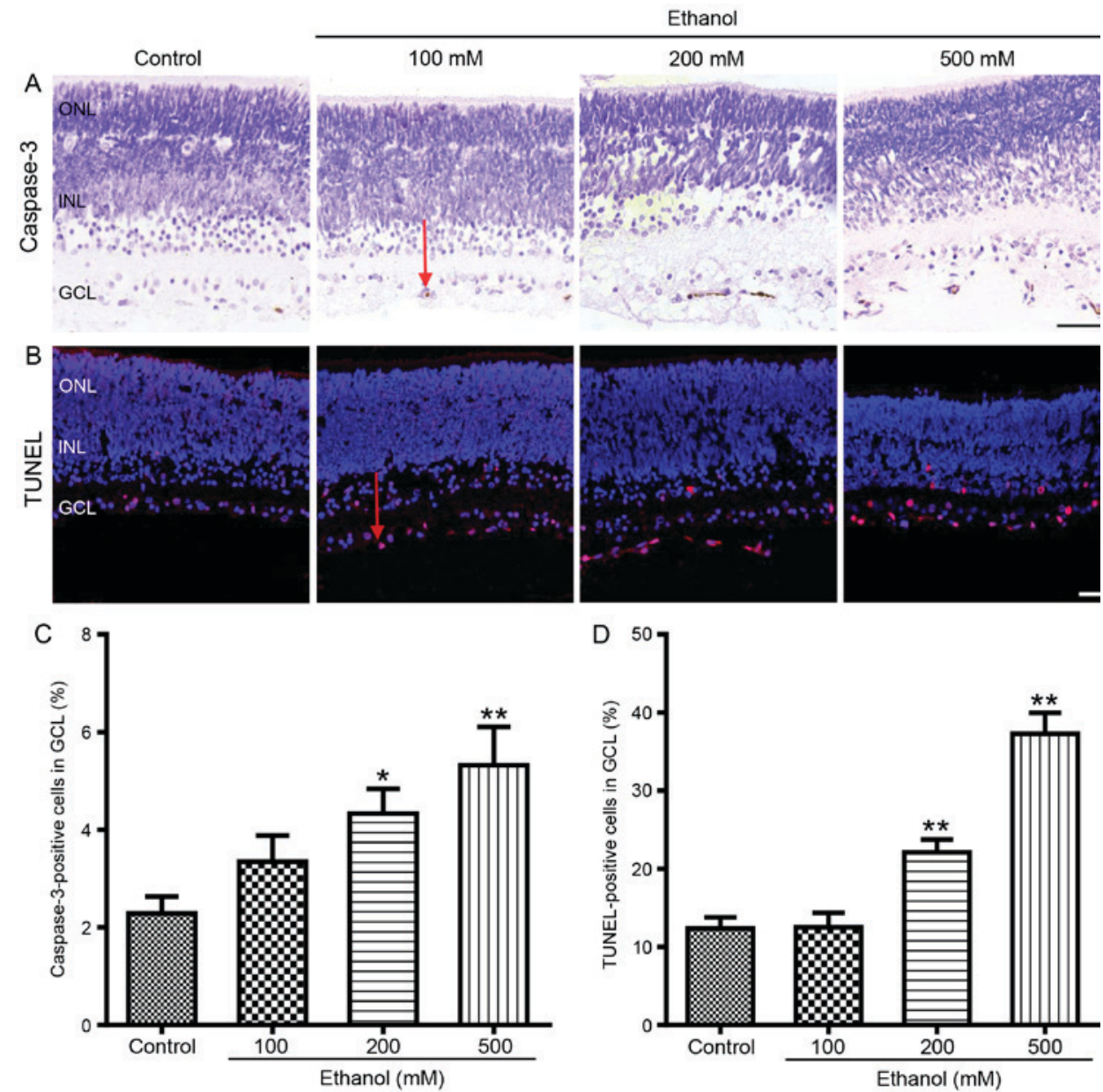

Figure 1. Ethanol exposure induces neuroapoptosis in P7 rat retinal GCL. Rat retinas were treated with ethanol (0, 100,200 or 500 mM; saline was used for the negative control) for $5 \mathrm{~h}$ and apoptotic cells were detected by caspase-3 immunohistochemistry and by TUNEL assays. (A) Representative photomicrograph of caspase-3-positive cells (brown color; indicted with a red arrow) in rat retinal GCL. Scale bar, $50 \mu \mathrm{m}$. (B) Representative photomicrograph of TUNEL-positive cells (red fluorescence indicated with a red arrow) in rat retinal GCL. Scale bar, $25 \mu \mathrm{m}$. (C) The mean percentages of caspase-3-positive cells from the various treatment groups. (D) The mean percentages of TUNEL-positive cells in retinal GCL following the various treatments. Comparisons were made by one-way analysis of variance followed by Tukey's post hoc test, and results are presented as the mean \pm standard error of the mean; $\mathrm{n}=5$ retinas/group ${ }^{*} \mathrm{P}<0.05$ and ${ }^{* *} \mathrm{P}<0.01$ vs. control. GCL, ganglion cell layer; INL, inner nuclear layer; ONL, outer nuclear layer; P7, postnatal day 7; TUNEL, terminal deoxynucleotidyl-transferase-mediated dUTP nick end labeling.

incubated in a TUNEL Label and Enzyme solution mix at $37^{\circ} \mathrm{C}$ for $1 \mathrm{~h}$, with two sections incubated in Label solution only to exclude false positive results. Sections were subsequently incubated for $5 \mathrm{~min}$ with DAPI at room temperature. The TUNEL-positive cells were counted in a double-blinded manner from five randomly selected and discontinuous sampling areas under high magnification using a Leica TCS SP8 microscope (Leica Microsystems GmbH).

Quantitative cell counts. Five discontinuous images in each retina were randomly captured under high magnification (x200). A total of 25 randomly selected and discontinuous views from 5 retinas per group were analyzed for quantitative cell count ( $n=5$ retinas/group). The number of apoptotic cells, either caspase-3 positive (visible cellular structures stained brown in color) or TUNEL-positive (indicated by red fluorescence), were counted in the retinal ganglion cell layer (GCL) using Image-Pro Plus 6.0 (Media Cybernetics Inc., Rockville, $\mathrm{MD}, \mathrm{USA}$ ) and the percentage of apoptotic cells in the rat GCL was calculated.
Statistical analysis. Data in the figures are presented as the mean \pm standard error of the mean and analyzed with GraphPad Prism 5 software (GraphPad Software Inc., La Jolla, CA, USA). One-way analysis of variance (ANOVA) or the non-parametric Kruskal-Wallis test was used for comparisons among groups with different concentrations of ethanol, dopamine or drug treatments, either together or separately, followed by Tukey's or Fisher's least significant difference post hoc test. Two-way ANOVA was used for comparisons among groups with or without ethanol and dopamine. The Mann-Whitney test or Kruskal-Wallis test was used to compare data without normality or equal variances between groups, and a P-value $<0.05$ was considered to indicate a statistically significant difference.

\section{Results}

Ethanol induces neuroapoptosis in developing rat retina in a dose-dependent manner. Caspase-3 immunohistochemistry and TUNEL staining were performed on whole-mount retinas 

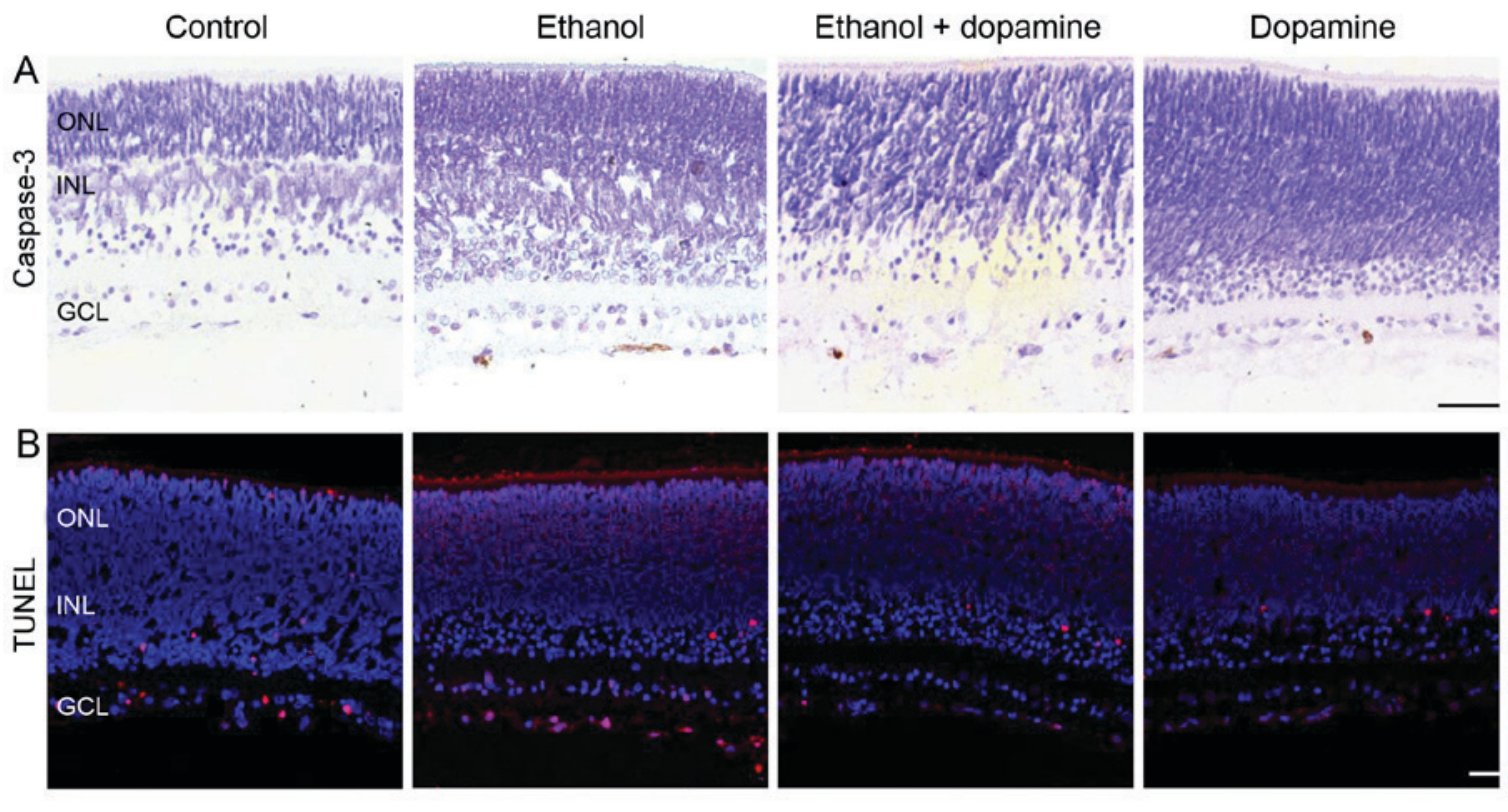

C
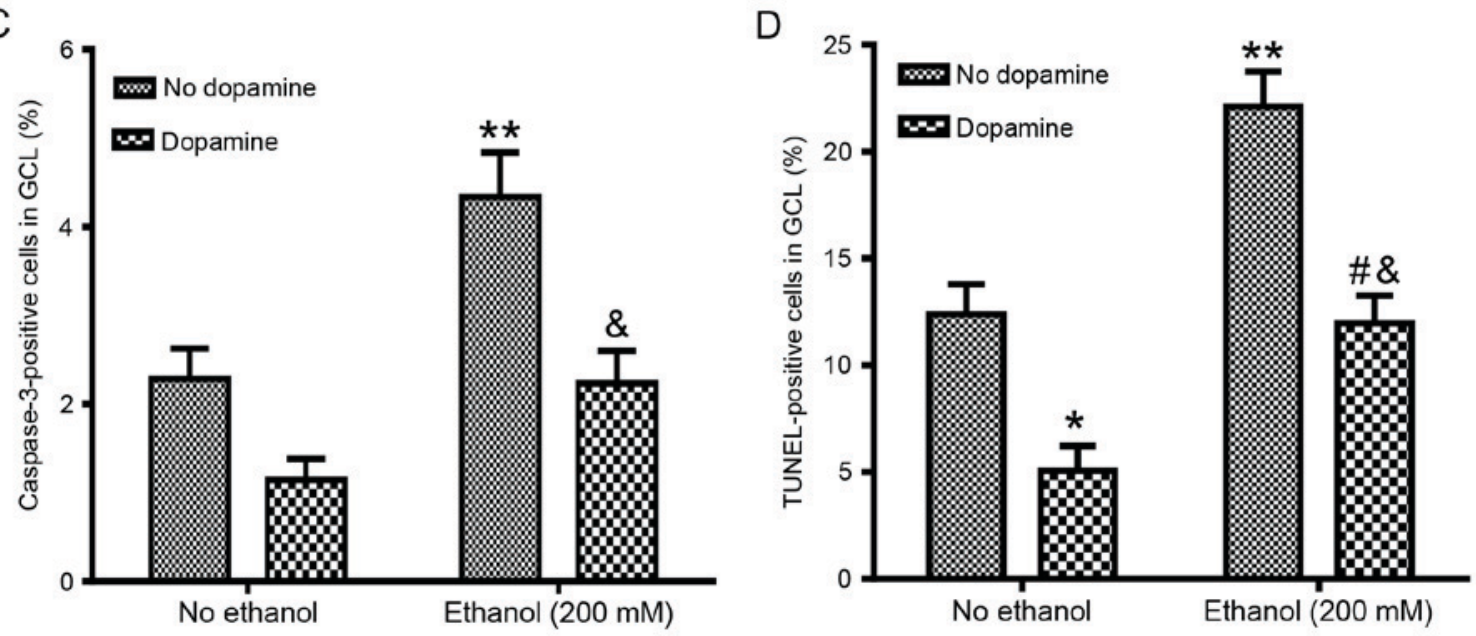

Figure 2. Effects of dopamine on ethanol-induced neuroapoptosis in P7 rat GCL. Rat retinas were treated with or without $200 \mathrm{mM}$ ethanol for $5 \mathrm{~h}$ in the absence or presence of $10 \mu \mathrm{M}$ dopamine. (A) Representative photomicrographs of caspase-3-positive cells (brown) in rat retinal GCL. Scale bar, $50 \mu \mathrm{m}$. (B) Representative photomicrographs of TUNEL-positive cells (red) in rat retinal GCL. Scale bar, $25 \mu \mathrm{m}$. (C) Mean percentage of caspase-3-positive cells in retinal GCL from the different treatment groups. (D) Mean percentage of TUNEL-positive cells in retinal GCL. Comparisons were made by one-way analysis of variance followed by Tukey's post hoc test, and results are presented as the mean \pm standard error of the mean; $n=5$ retinas/group. ${ }^{*} \mathrm{P}<0.05$ and ${ }^{* *} \mathrm{P}<0.01$ vs. control; ${ }^{\#} \mathrm{P}<0.05$ vs. dopamine alone; ${ }^{\circledR} \mathrm{P}<0.01$ vs. ethanol alone. GCL, ganglion cell layer; INL, inner nuclear layer; ONL, outer nuclear layer; $\mathrm{P} 7$, postnatal day 7; TUNEL, terminal deoxynucleotidyl-transferase-mediated dUTP nick end labeling.

to evaluate the effects of alcohol on developing rats in vitro. The results demonstrated that ethanol exposure increased the number of apoptotic cells in P7 rat GCL in a dose-dependent manner (Fig. 1). In particular, $100 \mathrm{mM}$ ethanol treatment for $5 \mathrm{~h}$ did not appear to affect the percentage of caspase-3-positive or TUNEL-positive cells in the retinal GCL of P7 rats. However, retinas cultured with 200 or $500 \mathrm{mM}$ ethanol exhibited a significant increase in apoptotic cells: The number of caspase-3-positive cells increased from $2.3 \pm 0.4$ to $4.3 \pm 0.5 \%(\mathrm{P}<0.05)$ and $5.3 \pm 0.8 \%$ $(\mathrm{P}<0.01)$, respectively (Fig. 1A and $\mathrm{C})$; and the TUNEL-positive cells increased from $12.4 \pm 1.4$ to $22.1 \pm 1.7 \%(\mathrm{P}<0.01)$ and $37.3 \pm 2.7 \%(\mathrm{P}<0.01)$, respectively (Fig. 1B and D). As $200 \mathrm{mM}$ ethanol is closer to the blood alcohol concentration in patients with severe alcohol intoxication (25) and may better-simulate clinical scenarios, $200 \mathrm{mM}$ ethanol was used in the following experiments, rather than $500 \mathrm{mM}$ ethanol.
Effects of dopamine on alcohol-induced neuroapoptosis in rat GCL. P7 rat retinas were treated with or without ethanol (200 mM) and with or without exogenous dopamine $(10 \mu \mathrm{M})$ (Fig. 2). Retinas treated with dopamine alone exhibited a reduction in neuronal apoptosis compared with untreated control retinas, with the number of caspase-3-positive cells reduced from $2.3 \pm 0.4$ to $1.1 \pm 0.2 \%$, although this reduction was determined to be non-significant $(\mathrm{P}=0.147$; Fig. $2 \mathrm{~A}$ and C), and the number of TUNEL-positive cells was significantly reduced from $12.4 \pm 1.4$ to $5.1 \pm 1.2 \%$ ( $\mathrm{P}<0.05$; Fig. $2 \mathrm{~B}$ and $\mathrm{D})$. Retinas co-treated with ethanol and dopamine exhibited a significant reduction in ethanol-induced neuroapoptosis, with the caspase-3-positive cells reduced from $4.3 \pm 0.5$ to $2.2 \pm 0.37 \%(\mathrm{P}<0.01$ vs. ethanol alone; Fig. $2 \mathrm{~A}$ and $\mathrm{C})$, and the TUNEL-positive cells were reduced from $22.1 \pm 1.65$ to $12.0 \pm 1.32 \%(\mathrm{P}<0.01$ vs. ethanol alone; Fig. $2 \mathrm{~B}$ and $\mathrm{D})$. 

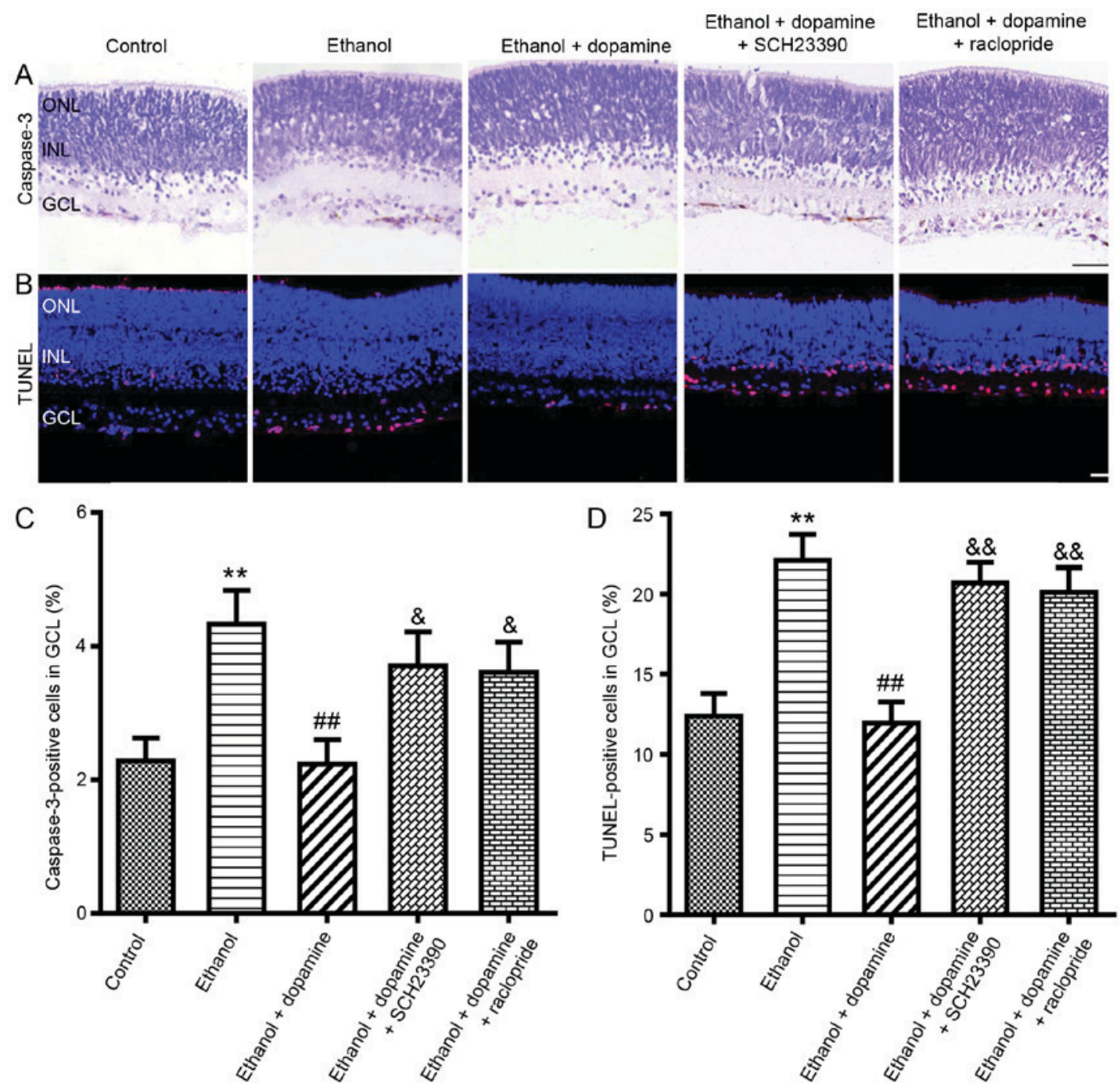

Figure 3. D1R and D2R are involved in the protective effects of dopamine against ethanol-induced neuroapoptosis in P7 rat retinas. Retinas were treated with $200 \mathrm{mM}$ ethanol and $10 \mu \mathrm{M}$ dopamine in the absence or presence of D1R antagonist SCH23390 or D2R antagonist raclopride for $5 \mathrm{~h}$. (A) Representative photomicrographs of caspase-3-positive cells (brown) in rat retinal GCL. Scale bar, $50 \mu \mathrm{m}$. (B) Representative photomicrographs of TUNEL-positive cells (red) in rat retinal GCL. Scale bar, $25 \mu \mathrm{m}$. (C) Mean apoptosis percentages of caspase-3-positive cells in retinal GCL in the different treatment groups. (D) Percentages of TUNEL-positive cells in retinal GCL. Comparisons were made by one-way analysis of variance (Kruskal-Wallis test for TUNEL) followed by Tukey's (Dunn's for TUNEL) post hoc test, and results are presented as the mean \pm standard error of the mean; $\mathrm{n}=5$ retinas/group. ${ }^{* *} \mathrm{P}<0.01$ vs. control; ${ }^{\# \#} \mathrm{P}<0.01$ vs. ethanol alone; ${ }^{\circledR} \mathrm{P}<0.05$ and ${ }^{\&} \mathrm{P}<0.01$ vs. ethanol + dopamine. D1R, dopamine D1 receptor; GCL, ganglion cell layer; INL, inner nuclear layer; ONL, outer nuclear layer; P7, postnatal day 7; TUNEL, terminal deoxynucleotidyl-transferase-mediated dUTP nick end labeling.

Exogenous dopamine treatment also significantly reduced $500 \mathrm{mM}$ ethanol-induced neuroapoptosis in the retinal GCL of $\mathrm{P} 7$ rats (data not shown).

$D 1 R, D 2 R$ and $A A 2 A R$ are involved in the neuroprotective effects of dopamine against alcohol-induced neuroapoptosis. To further explore the mechanisms of dopamine against alcohol-induced neuronal apoptosis, the roles of D1R and D2R activation against alcohol-induced retinal apoptosis were examined (Fig. 3), as well as the role of AA2AR (Fig. 4), as the dopamine receptors form heteromeric complexes that are comprised of D1R, D2R and AA2AR. The D1-like receptor antagonist $\mathrm{SCH} 23390(10 \mu \mathrm{M})$ significantly reduced the protective effects of dopamine against ethanol-induced neuroapoptosis, with the mean number of caspase-3-positive cells increased from $2.2 \pm 0.4$ to $3.7 \pm 0.5 \%(\mathrm{P}<0.05$; Fig. $3 \mathrm{~A}$ and $\mathrm{C}$ ), and the mean number of TUNEL-positive cells increased from $12.0 \pm 1.3$ to $20.7 \pm 1.3 \%$ ( $\mathrm{P}<0.01$; Fig. 3B and D). Co-treatment with the D2-like receptor antagonist raclopride $(40 \mu \mathrm{M})$ significantly increased the number of caspase-3-positive cells from $2.2 \pm 0.4$ to $3.6 \pm 0.5 \%(\mathrm{P}<0.05)$ and the number of TUNEL-positive cells from $12.0 \pm 1.3$ to $20.1 \pm 1.5 \%$, compared with retinas treated with ethanol and dopamine $(\mathrm{P}<0.01$; Fig. 3). Similar results were observed in retinas co-treated with the AA2AR antagonist SCH58261 $(100 \mathrm{nM})$, in which the mean number of caspase-3-positive cells increased from $2.2 \pm 0.4$ to $3.7 \pm 0.6 \%$ ( $\mathrm{P}<0.05$; Fig. $4 \mathrm{~A}$ and $\mathrm{C}$ ) and the number of TUNEL-positive cells increased from $12.0 \pm 1.3$ to $20.6 \pm 2.4 \%$, compared with retinas treated with ethanol and dopamine $(\mathrm{P}<0.05$; Fig. $4 \mathrm{~B}$ and $\mathrm{D})$. The results of a pilot study (24) demonstrated that treatment with antagonists alone did not induce neuroapoptosis; therefore, in the present study, incubations with antagonists alone were not performed. 

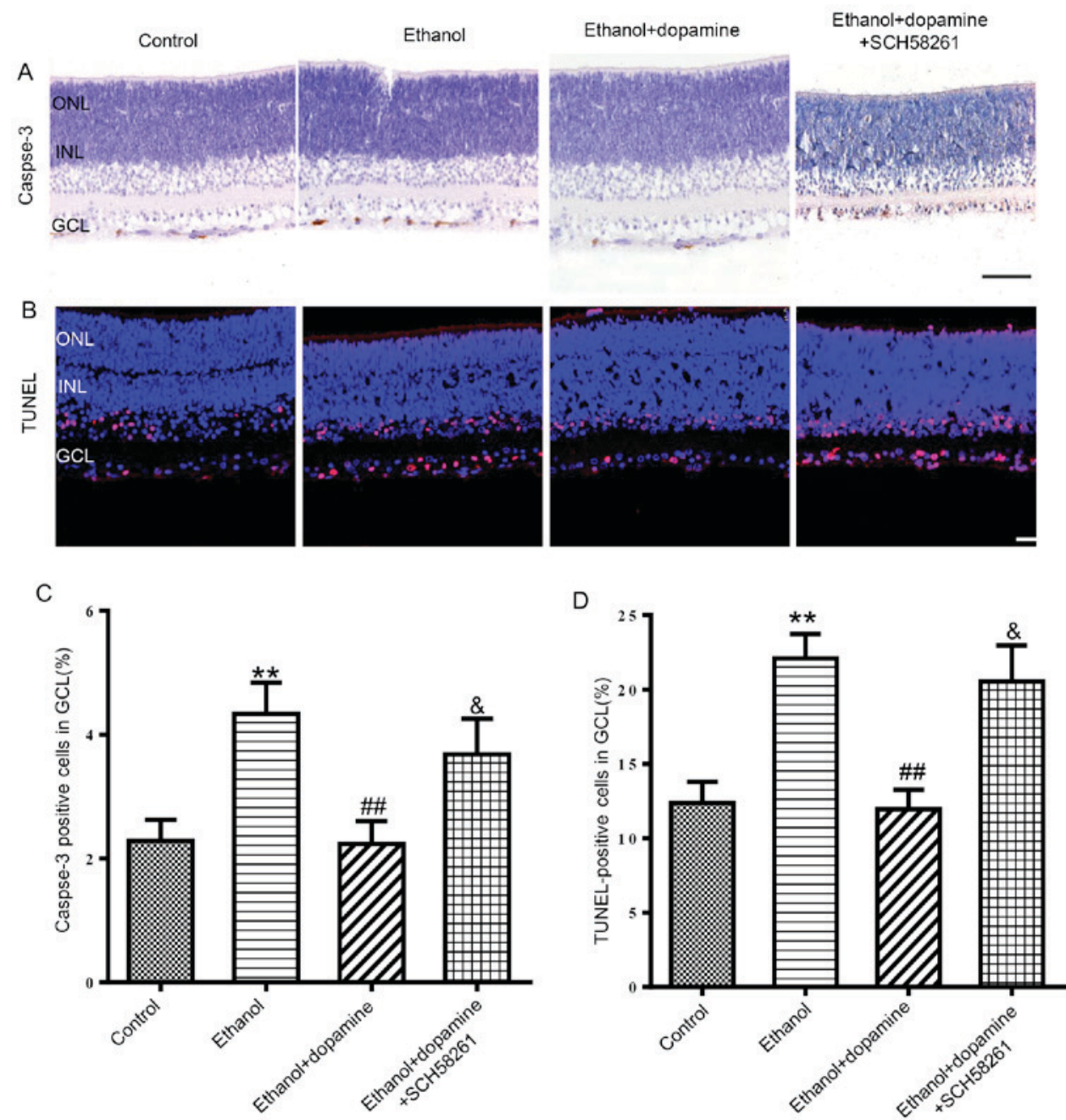

Figure 4. AA2AR is involved in the protective effect of dopamine against ethanol-induced neuroapoptosis in $\mathrm{P} 7 \mathrm{rat}$ retina. Retinas were treated with $200 \mathrm{mM}$ ethanol and $10 \mu \mathrm{M}$ dopamine in the absence or presence of AA2AR antagonist SCH58261 for $5 \mathrm{~h}$. (A) Representative photomicrographs of caspase-3 positive cells (brown) in rat retinal GCL. Scale bar, $50 \mu \mathrm{m}$. (B) Representative photomicrographs of TUNEL-positive cells (red) in rat retinal GCL. Scale bar, $25 \mu \mathrm{m}$. (C) The mean percentages of caspase-3 positive cells in retinal GCL in different groups. (D) The mean percentages of TUNEL-positive cells in retinal GCL. Comparisons were made by one-way analysis of variance (Kruskal-Wallis test for TUNEL) followed by Turkey (Dunn's for TUNEL) post-test, and results are presented as the mean \pm standard error of the mean; $\mathrm{n}=5$ retinas/group. ${ }^{* *} \mathrm{P}<0.01 \mathrm{vs}$. control; ${ }^{\# \#} \mathrm{P}<0.01$ vs. ethanol alone; ${ }^{\circledR} \mathrm{P}<0.05 \mathrm{vs}$. ethanol + dopamine. AA2AR, adenosine A2A receptor; GCL, ganglion cell layer; INL, inner nuclear layer; ONL, outer nuclear layer; P7, postnatal day 7; TUNEL, terminal deoxynucleotidyl-transferase-mediated dUTP nick end labeling.

Role of cAMP/PKA signaling in the dopamine-induced neuroprotective action against alcohol-induced neuroapoptosis. The activation of AA2AR and D1R has been previously reported to initiate a cascade of biochemical events, including the activation of $\mathrm{AC}$ and the stimulation of cAMP-dependent protein kinase $(26,27)$. Therefore, the present study explored the relationship between the cAMP/PKA signaling pathway and the protective action of dopamine against alcohol-induced neuronal apoptosis. Treatment with either an AC inhibitor, SQ22536 $(100 \mu \mathrm{M})$, or a PKA inhibitor, H-89 $(1 \mu \mathrm{M})$, significantly attenuated the protective effects of dopamine against ethanol-induced neuronal apoptosis (Fig. 5). In particular, ethanol + dopamine treated retinas that were co-treated with either SQ22536 or H-89 exhibited an increase in the number of caspase-3-positive cells from $2.2 \pm 0.4$ to $3.7 \pm 0.4 \%(\mathrm{P}<0.05)$ and $3.7 \pm 0.5 \%(\mathrm{P}<0.05)$, respectively (Fig. $5 \mathrm{~A}$ and $\mathrm{C})$. In addition, SQ22536 and $\mathrm{H}-89$ treatments increased the number of TUNEL-positive cells from $12.0 \pm 1.3$ to $20.6 \pm 1.9 \%$ ( $\mathrm{P}<0.05$ ) and $21.0 \pm 2.2 \%(\mathrm{P}<0.05)$, respectively (Fig. $5 \mathrm{~B}$ and $\mathrm{D})$.

\section{Discussion}

Results from the present study demonstrated that ethanol treatment was able to induce neuronal apoptosis in developing P7 rat retinal GCL in a dose-dependent manner. Administration of exogenous dopamine was revealed to alleviate the alcohol-induced neuroapoptosis; whereas the inhibition of AA2AR, D1R or D2R partially reversed the protective effects of dopamine. In addition, it was determined that the cAMP/PKA signaling pathway may also be partially involved in the protective action of dopamine against alcohol-induced neuronal apoptosis in developing rat GCL.

As previously reported from studies in animals (28), children with FASD exhibit retinal developmental defects (29); in rodents, postnatal days 4-10 were reported to be equivalent to the third trimester of pregnancy in humans. Anesthesia- and alcohol-induced neuroapoptosis in the rodent brain is age dependent, and developing rodent brains are most sensitive to anesthetics and alcohol at the peak of synaptogenesis (P7) 


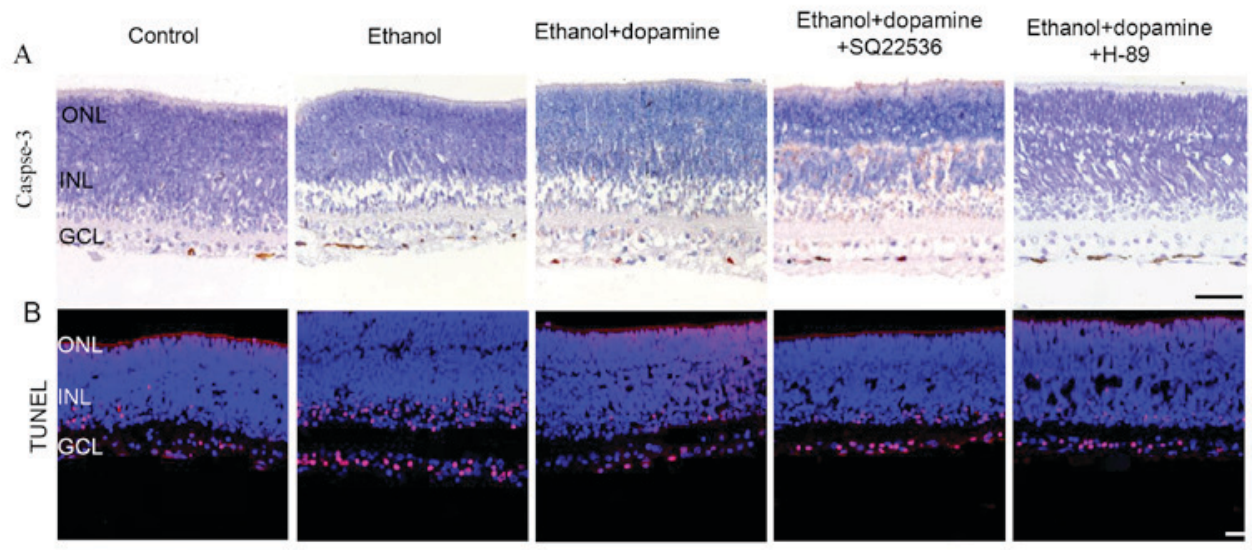

C

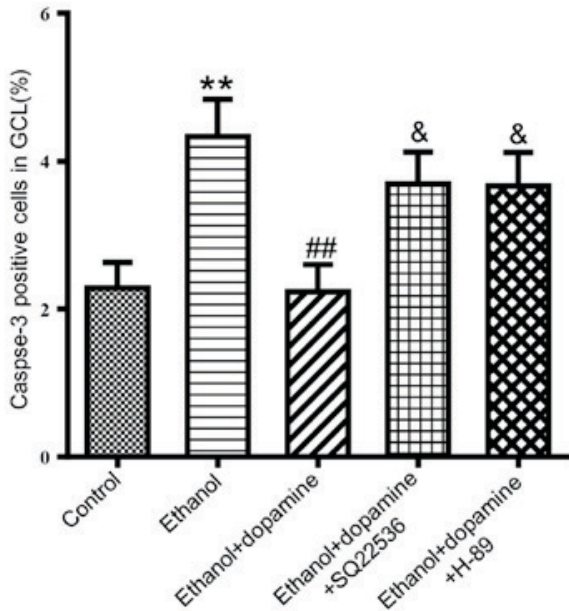

D

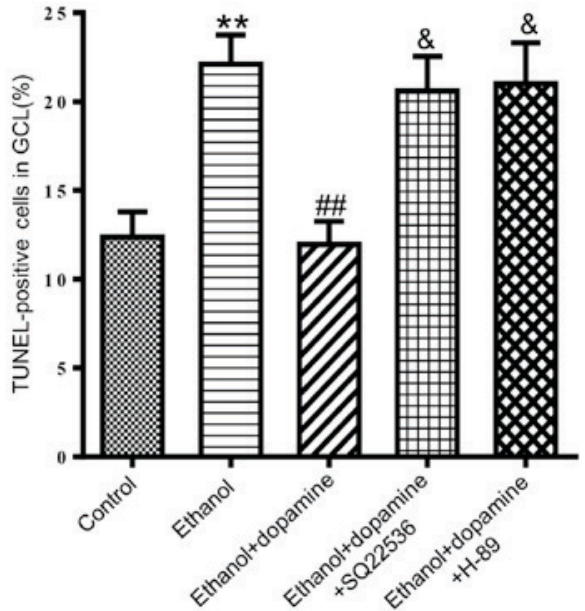

Figure 5. Cyclic adenosine monophosphate/PKA signaling pathway is involved in the protective effects of dopamine against ethanol-induced neuroapoptosis in P7 rat retina. Retinas were treated with $200 \mathrm{mM}$ ethanol and $10 \mu \mathrm{M}$ dopamine in the absence or presence of either the adenylyl cyclase antagonist SQ22536 or the PKA antagonist H-89 for 5 h. (A) Representative photomicrographs of caspase-3-positive cells (brown) in rat retinal GCL. Scale bar, $50 \mu$ m. (B) Representative photomicrographs of TUNEL-positive cells (red) in rat retinal GCL. Scale bar, $25 \mu \mathrm{m}$. (C) The mean number of caspase-3-positive cells in retinal GCL in the different treatment groups. (D) The percentages of TUNEL-positive cells in retinal GCL. Comparisons were made by one-way analysis of variance (Kruskal-Wallis test for TUNEL) followed by Tukey's (Dunn's for TUNEL) post hoc test, and results are presented as the mean \pm standard error of the mean; $\mathrm{n}=5$ retinas per group. ${ }^{* *} \mathrm{P}<0.01$ vs. control; ${ }^{\# \#} \mathrm{P}<0.01$ vs. ethanol alone; ${ }^{\&} \mathrm{P}<0.05$ vs. ethanol + dopamine. GCL, ganglion cell layer; INL, inner nuclear layer; ONL, outer nuclear layer; P7, postnatal day 7; PKA, protein kinase A; TUNEL, terminal deoxynucleotidyl-transferase-mediated dUTP nick end labeling.

and least sensitive at the end of synaptogenesis (P14) $(30,31)$. In the developing rodent retina, $\mathrm{P} 7$ corresponds to a time point just before birth in humans (32). The present study was able to consistently induce widespread neuronal apoptosis by treating P7 retinas with $200 \mathrm{mM}$ ethanol for $5 \mathrm{~h}$ and, similar to previous reports on the effects of alcohol on the developing brain, demonstrated that alcohol exposure caused widespread neuroapoptosis in the retinas in a dose-dependent manner $(5,33)$. In contrast to brain slices and cell cultures, whole-mount retinal cultures possess similar organizational structures and physiological characteristics with the brain (34). In addition, whole-mount retinal cultures ensure structural and connective integrity of the neural network. Retinal cultures also exclude other factors that might confound results such as those factors associated with general anesthesia and noxious stimulations in intact animal models, including hypoxia, $\mathrm{CO}_{2}$ accumulation and stress (34). Therefore, the in vitro whole-mount retinal culture method used in the present study may be useful for studying the functions and mechanisms of the central nervous system.
Although ethanol concentrations in the fetal brain and retina may be hard to determine, the ethanol concentrations in the fetal brain and retina should at least be close to maternal blood ethanol concentration since ethanol easily passes through blood-brain barrier and blood-placenta barrier (35). According to previous reports, a single incident of alcohol intoxication during the early postnatal period was demonstrated to trigger apoptosis in GCL and in neurons at higher levels of the central nervous system (6). The average blood alcohol concentration (BAC) of patients with alcohol intoxication in an adult emergency room is reported to be $\sim 467 \mathrm{mg} / \mathrm{dl}(100 \mathrm{mM})$, and some reported to be $>600 \mathrm{mg} / \mathrm{dl}$ (25). A previous study demonstrated that ethanol induced neuroapoptosis in a timeand dose-dependent manner (36). In addition, a previous study demonstrated that ketamine induced rat retinal neuroapoptosis following incubation of the eyeballs for $5 \mathrm{~h}$ (24); therefore the eyeballs were incubated with ethanol for $5 \mathrm{~h}$ in the present study. Although $100 \mathrm{mM}$ ethanol did not significantly increase apoptosis in the present study, retinas treated with 200 or 
$500 \mathrm{mM}$ ethanol exhibited a significant increase in apoptosis, which was similar to a previous in vivo and in vitro study (36). Previous in vivo studies revealed that the optimal time for visualizing caspase- 3 activation was at $8 \mathrm{~h}$ following the first dose of subcutaneous ethanol administration, and the blood ethanol concentration reaches peak levels $(500 \mathrm{mg} / \mathrm{dl} ; 108.7 \mathrm{mM})$ at $3 \mathrm{~h}$ following the first dose (37). Previous in vitro studies demonstrated that the concentration-dependent increase in caspase-3 activity induced by ethanol (100-500 $\mathrm{mM})$ reached maximal levels at $\sim 12 \mathrm{~h}$ post-ethanol exposure (36). Therefore, the $100 \mathrm{mM}$ ethanol treatment used in the present study did not significantly increase apoptosis, which may be due to the short incubation time $(5 \mathrm{~h})$ or the incubation of the eyeball with ethanol in vitro rather than injecting the ethanol subcutaneously in vivo. In addition, ethanol evaporation cannot be completely ruled out in the present study, even though compensatory strategies were used.

The different percentages of neuroapoptosis detected by caspase-3 immunohistochemistry and the TUNEL assay in the present study may be due to the ephemeral phenomenon of the caspase- 3 assay or caspase- 3 independent neuronal apoptosis $(6,36)$. Although necrosis cannot be completely ruled out, the present study demonstrated that the percent of neuroapoptosis detected by the caspase-3 assay and the TUNEL assay increased as the concentration of ethanol increased from 200 to $500 \mathrm{mM}$, confirming that lower ethanol $(<500 \mathrm{mM})$ exposure caused neuronal death primarily in the form of apoptosis, as demonstrated in a previous study (36).

As a second messenger, cAMP modulates numerous physiological functions and pathophysiological changes; for example, cAMP has been reported to be involved in alcohol-induced neuroapoptosis as either a pro- or an anti-apoptotic messenger $(19,38)$. The present study demonstrated that inhibition of AC and PKA significantly reduced the protective effects of dopamine against alcohol-induced neuronal apoptosis. This result suggested that dopamine may be able to attenuate ethanol-induced neuroapoptosis partially through the activation of the cAMP/PKA signaling pathway, which is consistent with previous studies that reported a downregulation of intracellular cAMP and PKA following alcohol exposure $(19,39)$. Data from the present study are consistent with a previous report that suggested that cAMP attenuates apoptosis in developing hypothalamic cells (39). It should be noted that the present results differ from certain previous studies that evaluated the effects of alcohol on relatively mature neurons ( $>4-6$ weeks old), which demonstrated that alcohol exposure induced an increase in intracellular levels of cAMP and PKA type II regulatory subunits in the rat brain (20), as well as brain PKA activation in mice (40).

Dopamine is associated with aspectrumofneurophysiological processes, including the regulation of neuronal differentiation, axonal and/or dendritic growth in the developing brain and retina $(41,42)$. D1R and D2R were previously demonstrated to be widely distributed in the inner plexiform layer, the ganglion cell layer, the outer plexiform layer and the photoreceptors, where they are activated by dopamine released from dopaminergic amacrine cell and/or interplexiform dopaminergic cells in the retinal inner plexiform layer $(43,44)$. Although the activation of D1R is generally considered to be related to the increase in intracellular cAMP and enhancement of neuronal apoptosis and activation of $\mathrm{D} 2$ receptor is opposite, an increasing number of studies have reported that D1R and/or D2R may form different heteromeric complexes with AA2AR to produce different effects $(9,10)$. Furthermore, it has been postulated that D2R may be able to synergize with AA2AR to stimulate AC expression (45). In addition, to activate cAMP-dependent processes through the co-activation of D1R and D2R (46), dopamine may also activate a heterodimer of D1R and D2R to generate a calcium-dependent signaling pathway (47), indicating that dopamine heteroreceptor complexes, or the synergy between D2R and AA2AR, may be involved in the protective effects of dopamine. Therefore, it may be possible that the inhibition of D1R, D2R or AA2AR was able to bring the dopamine-induced reduction in apoptosis back to similar levels in retinas treated with ethanol alone. Furthermore, inhibition of the cAMP/PKA signaling pathway reduced the protective effects of dopamine on alcohol-induced neuroapoptosis in developing rat retina, indicating that cAMP/PKA signaling pathway may be involved in this process.

A few limitations to the present study should be noted. First, it is unclear whether dopamine heteroreceptor complexes or the synergy between D2R and AA2AR are involved in the protective action of dopamine on the alcohol-induced apoptosis that was observed in developing rat GCL. In addition, the intracellular levels of cAMP/PKA and the downstream targets of the cAMP/PKA signaling pathway, such as extracellular signal-regulated kinase $1 / 2$, proto-oncogene c-Akt and cAMP-responsive element-binding protein also need to be investigated. As neuroapoptosis in response to ethanol treatment was most marked at P7 in the rat GCL, the retinal GCL was the focus of the present study; future studies are required to analyze the effect of ethanol on other retinal layers.

In conclusion, the present study demonstrated that dopamine treatment was able to attenuate ethanol-induced neuroapoptosis in developing $\mathrm{P} 7$ rat retinas, possibly through the activation of D1R, D2R and AA2AR, as well as by upregulating the $\mathrm{CAMP} / \mathrm{PKA}$ signaling pathway.

\section{Acknowledgements}

This study was supported by The National Natural Science Foundation of China (Beijing, China; grant no. 81271263 to Jijian Zheng and grant no. 81270414 to Mazhong Zhang) and The Shanghai Municipal Commission of Health and Family Planning, Key Developing Disciplines (grant no. 2015ZB0106).

\section{References}

1. Clarren SK and Smith DW: The fetal alcohol syndrome. N Engl J Med 298: 1063-1067, 1978.

2. Sulik KK, Johnston MC and Webb MA: Fetal alcohol syndrome: Embryogenesis in a mouse model. Science 214: 936-938, 1981.

3. May PA, Gossage JP, Kalberg WO, Robinson LK, Buckley D, Manning $\mathrm{M}$ and Hoyme HE: Prevalence and epidemiologic characteristics of FASD from various research methods with an emphasis on recent in-school studies. Dev Disabil Res Rev 15: 176-192, 2009.

4. May PA, Baete A, Russo J, Elliott AJ, Blankenship J, Kalberg WO, Buckley D, Brooks M, Hasken J, Abdul-Rahman O, et al: Prevalence and characteristics of fetal alcohol spectrum disorders. Pediatrics 134: 855-866, 2014.

5. Ikonomidou C, Bittigau P, Ishimaru MJ, Wozniak DF, Koch C, Genz K, Price MT, Stefovska V, Hörster F, Tenkova T, et al: Ethanol-induced apoptotic neurodegeneration and fetal alcohol syndrome. Science 287: 1056-1060, 2000. 
6. Tenkova T, Young C, Dikranian K, Labruyere J and Olney JW: Ethanol-induced apoptosis in the developing visual system during synaptogenesis. Invest Ophthalmol Vis Sci 44: 2809-2817, 2003.

7. Creeley CE, Dikranian KT, Johnson SA, Farber NB and Olney JW: Alcohol-induced apoptosis of oligodendrocytes in the fetal macaque brain. Acta Neuropathol Commun 1: 23, 2013.

8. Olney JW: Focus on apoptosis to decipher how alcohol and many other drugs disrupt brain development. Front Pediatr 2: 81, 2014.

9. Beaulieu JM and Gainetdinov RR: The physiology, signaling, and pharmacology of dopamine receptors. Pharmacol Rev 63 182-217, 2011.

10. Beaulieu JM, Espinoza S and Gainetdinov RR: Dopamine receptors-IUPHAR Review 13. Br J Pharmacol 172: 1-23, 2015.

11. Naseer MI, Ullah I, Rasool M, Ansari SA, Sheikh IA, Bibi F, Chaudhary AG, Al-Qahtani MH and Kim MO: Downregulation of dopamine $\mathrm{D}_{1}$ receptors and increased neuronal apoptosis upon ethanol and PTZ exposure in prenatal rat cortical and hippocampal neurons. Neurol Sci 35: 1681-1688, 2014.

12. Vaarmann A, Kovac S, Holmström KM, Gandhi S and Abramov AY: Dopamine protects neurons against glutamate-induced excitotoxicity. Cell Death Dis 4: e455, 2013.

13. Li HZ, Guo J, Gao J, Han LP, Jiang CM, Li HX, Bai SZ, Zhang WH, Li GW, Wang LN, et al: Role of dopamine D2 receptors in ischemia/reperfusion induced apoptosis of cultured neonatal rat cardiomyocytes. J Biomed Sci 18: 18, 2011.

14. Canals M, Marcellino D, Fanelli F, Ciruela F, de Benedetti P, Goldberg SR, Neve K, Fuxe K, Agnati LF, Woods AS, et al: Adenosine A2A-dopamine D2 receptor-receptor heteromerization: Qualitative and quantitative assessment by fluorescence and bioluminescence energy transfer. J Biol Chem 278: 46741-46749, 2003.

15. D'Mello SR, Galli C, Ciotti T and Calissano P: Induction of apoptosis in cerebellar granule neurons by low potassium: Inhibition of death by insulin-like growth factor I and cAMP. Proc Natl Acad Sci USA 90: 10989-10993, 1993.

16. Meyer-Franke A, Kaplan MR, Pfrieger FW and Barres BA: Characterization of the signaling interactions that promote the survival and growth of developing retinal ganglion cells in culture. Neuron 15: 805-819, 1995

17. Hanson MG Jr, Shen S, Wiemelt AP, McMorris FA and Barres BA: Cyclic AMP elevation is sufficient to promote the survival of spinal motor neurons in vitro. J Neurosci 18: 7361-7371, 1998.

18. Sapru MK, Diamond I and Gordon AS: Adenosine receptors mediate cellular adaptation to ethanol in NG108-15 cells. J Pharmacol Exp Ther 271: 542-548, 1994.

19. Han JY, Jeong JY, Lee YK, Roh GS, Kim HJ, Kang SS, Cho GJ and Choi WS: Suppression of survival kinases and activation of JNK mediate ethanol-induced cell death in the developing rat brain. Neurosci Lett 398: 113-117, 2006.

20. Gigante ED, Santerre JL, Carter JM and Werner DF: Adolescent and adult rat cortical protein kinase A display divergent responses to acute ethanol exposure. Alcohol 48: 463-470, 2014

21. Liu Z, Liu Y, Gao R, Li H, Dunn T, Wu P, Smith RG, Sarkar PS and Fang X: Ethanol suppresses PGC-1 $\alpha$ expression by interfering with the cAMP-CREB pathway in neuronal cells. PLoS One 9: e104247, 2014

22. Wang X, Yang Z, Sun Y, Zhou H, Chu G, Zhang J and Meng X: Ethanol activation of PKA mediates single-minded 2 expression in neuronal cells. Mol Neurobiol 52: 1234-1244, 2015.

23. Kadam RS, Williams J, Tyagi P, Edelhauser HF and Kompella UB: Suprachoroidal delivery in a rabbit ex vivo eye model: Influence of drug properties, regional differences in delivery, and comparison with intravitreal and intracameral routes. Mol Vis 19: 1198-1210, 2013.

24. Dong J, Gao L, Han J, Zhang J and Zheng J: Dopamine attenuates ketamine-induced neuronal apoptosis in the developing rat retina independent of early synchronized spontaneous network activity. Mol Neurobiol 54: 3407-3417, 2017.

25. Minion GE, Slovis CM and Boutiette L: Severe alcohol intoxication: A study of 204 consecutive patients. J Toxicol Clin Toxicol 27: 375-384, 1989.

26. Fredholm BB, Arslan G, Halldner L, Kull B, Schulte G and Wasserman W: Structure and function of adenosine receptors and their genes. Naunyn Schmiedebergs Arch Pharmacol 362: 364-374, 2000.
27. Song ZM, Undie AS, Koh PO, Fang YY, Zhang L, Dracheva S, Sealfon SC and Lidow MS: D1 dopamine receptor regulation of microtubule-associated protein-2 phosphorylation in developing cerebral cortical neurons. J Neurosci 22: 6092-6105, 2002.

28. Dursun I, Jakubowska-Doğru E, van der List D, Liets LC, Coombs JL and Berman RF: Effects of early postnatal exposure to ethanol on retinal ganglion cell morphology and numbers of neurons in the dorsolateral geniculate in mice. Alcohol Clin Exp Res 35: 2063-2074, 2011.

29. Ribeiro IM, Vale PJ, Tenedorio PA, Rodrigues PA, Bilhoto MA and Pereira HC: Ocular manifestations in fetal alcohol syndrome. Eur J Ophthalmol 17: 104-109, 2007.

30. Bayer SA, Altman J, Russo RJ and Zhang X: Timetables of neurogenesis in the human brain based on experimentally determined patterns in the rat. Neurotoxicology 14: 83-144, 1993.

31. Yon JH, Daniel-Johnson J, Carter LB and Jevtovic-Todorovic V: Anesthesia induces neuronal cell death in the developing rat brain via the intrinsic and extrinsic apoptotic pathways. Neuroscience 135: 815-827, 2005.

32. Cheng Y,HeL,Prasad V,Wang S and Levy RJ: Anesthesia-induced neuronal apoptosis in the developing retina: A window of opportunity. Anesth Analg 121: 1325-1335, 2015.

33. Ikonomidou C, Bosch F, Miksa M, Bittigau P, Vöckler J, Dikranian K, Tenkova TI, Stefovska V, Turski L and Olney JW: Blockade of NMDA receptors and apoptotic neurodegeneration in the developing brain. Science 283: 70-74, 1999.

34. Ogilvie JM, Speck JD, Lett JM and Fleming TT: A reliable method for organ culture of neonatal mouse retina with long-term survival. J Neurosci Methods 87: 57-65, 1999

35. Cammer W, Tansey F, Abramovitz M, Ishigaki S and Listowsky I: Differential localization of glutathione-S-transferase Yp and $\mathrm{Yb}$ subunits in oligodendrocytes and astrocytes of rat brain. J Neurochem 52: 876-883, 1989.

36. Nowoslawski L, Klocke BJ and Roth KA: Molecular regulation of acute ethanol-induced neuron apoptosis. J Neuropathol Exp Neurol 64: 490-497, 2005.

37. Young C, Klocke BJ, Tenkova T, Choi J, Labruyere J, Qin YQ, Holtzman DM, Roth KA and Olney JW: Ethanol-induced neuronal apoptosis in vivo requires BAX in the developing mouse brain. Cell Death Differ 10: 1148-1155, 2003

38. Insel PA, Zhang L, Murray F, Yokouchi $\mathrm{H}$ and Zambon AC: Cyclic AMP is both a pro-apoptotic and anti-apoptotic second messenger. Acta Physiol (Oxf) 204: 277-287, 2012.

39. Boyadjieva NI and Sarkar DK: Cyclic adenosine monophosphate and brain-derived neurotrophic factor decreased oxidative stress and apoptosis in developing hypothalamic neuronal cells: Role of microglia. Alcohol Clin Exp Res 37: 1370-1379, 2013.

40. Balino P, Ledesma JC and Aragon CM: In vivo study of ethanol-activated brain protein kinase A: Manipulations of Ca2+ distribution and flux. Alcohol Clin Exp Res 38: 629-640, 2014

41. Girault JA and Greengard P: The neurobiology of dopamine signaling. Arch Neurol 61: 641-644, 2004.

42. Witkovsky P: Dopamine and retinal function. Doc Ophthalmol 108: 17-40, 2004.

43. Bjelke B, Goldstein M, Tinner B, Andersson C, Sesack SR, Steinbusch HW, Lew JY, He X, Watson S, Tengroth B and Fuxe K: Dopaminergic transmission in the rat retina: Evidence for volume transmission. J Chem Neuroanat 12: 37-50, 1996.

44. Ogata G, Stradleigh TW, Partida GJ and Ishida AT: Dopamine and full-field illumination activate D1 and D2-D5-type receptors in adult rat retinal ganglion cells. J Comp Neurol 520: 4032-4049, 2012.

45. Kudlacek O, Just H, Korkhov VM, Vartian N, Klinger M, Pankevych H, Yang Q, Nanoff C, Freissmuth M and Boehm S: The human D2 dopamine receptor synergizes with the A2A adenosine receptor to stimulate adenylyl cyclase in PC12 cells. Neuropsychopharmacology 28: 1317-1327, 2003.

46. Hopf FW, Cascini MG, Gordon AS, Diamond I and Bonci A Cooperative activation of dopamine D1 and D2 receptors increases spike firing of nucleus accumbens neurons via G-protein betagamma subunits. J Neurosci 23: 5079-5087, 2003.

47. Ng J, Rashid AJ, So CH, O'Dowd BF and George SR: Activation of calcium/calmodulin-dependent protein kinase IIalpha in the striatum by the heteromeric D1-D2 dopamine receptor complex. Neuroscience 165: 535-541, 2010 